\title{
Complexidade e transdisciplinaridade: novos caminhos para o estu- do das normas legais
}

\author{
Complexity and transdisciplinarity: new ways for the study of legal standards
}

Danielle Ferreira Medeiro da Silva de Araújo ${ }^{\dagger *}$, Jódiney Benedito Marques

Como citar esse artigo. de Araújo, D.F.M.S; Marques, JB. Complexidade e transdisciplinaridade: novos caminhos para o estudo das normas legais. Revista Mosaico. 2018 Jan./Jun.; 09 (1): 35-43.

\begin{abstract}
Resumo
A temática do trabalho propõe-se a reflexão sobre a necessidade de um estudo e ensino das normas legais transpondo os pilares da racionalidade lógico-formal. O objetivo é apresentar novos caminhos com base na teoria da complexidade e transdisciplinaridade a fim de se ampliar o universo de estudo e possibilitar estratégias inovadoras para transformação social. A metodologia apoia-se na teoria fundamentada, com a utilização do método de pesquisa bibliográfica. Os resultados apresentados apontam para uma dinâmica educacional que evidencie a capacidade dialógica, inclusiva e reflexiva na busca de um processo de criação coletiva de conhecimento.

Palavras-Chave: Complexidade; Normas legais; Normas sociais; Transdisciplinaridade.
\end{abstract}

\begin{abstract}
The thematic of the work proposes the reflection on the necessity of a study and teaching of the legal norms transposing the pillars of logical-formal rationality. The objective is to present new paths based on the theory of complexity and transdisciplinarity in order to expand the universe of study and to enable innovative strategies for social transformation. The methodology is based on the theory founded, using the method of bibliographic research. The results presented point to an educational dynamic that evidences the dialogic, inclusive and reflexive capacity in the search for a process of collective creation of knowledge.

Keywords:: Complexity; Legal norms; Social norms; Transdisciplinarity
\end{abstract}

A Constituição brasileira enumerou um rol de liberdades e direitos, em geral os direitos sociais (art. $6^{\circ}$ e $7^{\circ}$ ), complementando com as disposições do Título VIII, "Da ordem social", em que se definem os modos ou estruturas básicas de efetivação dos direitos sociais (arts. 193 a 232).Todavia, apesar da positivação dos direitos sociais, a problemática que separa a tutela destes direitos garantidos na Carta Magna e sua efetividade, ainda permanecem atuaisno Brasil, apresentandose como tema desafiador para docentes, estudantes e operadores do Direito.

Compreendendo-seas ordenações valorativas, assim como a construção do conhecimento e as estruturas sociais,como reflexo das interações entre o grau de riquezas, os interesses, as necessidades fundamentais e as relações de forças que operam na vida social (WOLKMER, 2001), o estudo e ensino das normas legais requerem a análise do fato subjacente à norma jurídica (que pode ser um fato econômico, geográfico, demográfico, de ordem técnica), a significação ou valor que se confere ao fato e a regra como representação de integração entre estes elementos, conferindo assim uma unidade concreta, que se compõe pela interação dinâmica e dialética entre fato, valor e norma. (REALE, 2002)

Para o estudo e ensino das normas legais que se aproxime da complexidade do tempo presente, novos caminhos para além da racionalidade herdada pela cultura jurídica monista, do positivismo e da disciplinaridade devem ser abertos oportunizando a complementariedade de outros saberes, em uma interação ecológica , com vistas à formulação de novas estratégias de resolução

Afiliação dos autores: † Mestranda do Programa de Pós-Graduação em Estado e Sociedade, do Centro de Formação em Ciências Humanas e Sociais da Universidade Federal do Sul

* Mestrando do Programa de Pós-Graduação em Economiae Gestão Empresarial da Universidade Cândido Mendes (UCAM). 
dos problemas sociais ainda recorrentes no Brasil. Trata-se de descortinar o poder simbólico por trás das normas legais e de se analisar de forma crítica e reflexiva como as construções sociais fundamentadas na desigualdade ainda operam como base em modos de vida que são deslegitimados e criminalizados pela lei, em um universo de exclusão e de falta de acesso aos direitos.

O trabalho utiliza-se da teoria fundamentada como metodologia que se compõe na união de teorias a experiências e dados com a finalidade de amplificar o entendimento sobre conceitos, proporcionando assim um guia significativo para a ação. A pesquisa bibliográfica será o método empregado, a partir da investigação em registros disponíveis em fontes impressas e digitais sobre a temática, além de registros estatísticos referentes a violações de direitos.

\section{A normatividade no espaço social brasileiro}

\section{As normas legais e o seu poder simbólico}

As normas legais ao mesmo tempo em que influenciam o mundo social também são influenciadas por ele. "A ilusão juridicista não se impõe apenas ao pesquisador. Ela age na própria realidade." (BOURDIEU, 2004)Para Bourdieu (2009, p.237) "o direito é a forma por excelência do discurso atuante, capaz, por sua própria força, de produzir efeitos. Não é demais dizer que ele faz o mundo social, mas com a condição de se não esquecer que ele é feito por este". Assim, a autonomia absoluta das normas legais não seria possível porque todo o seu caráter objetivo, universal e impessoal produziria efeitos no mundo social, mas não o esgotaria. A compreensão dialética da norma legal aparece na teoria da tridimensionalidade jurídica que supera o sociologismo jurídico e o criticismo formal ao reconhecer que o ponto de partida da norma encontra-se no fato em direção a um determinado valor, ou seja, "fato, valor e norma estão sempre presentes e correlacionados em qualquer expressão da vida jurídica." (REALE, 2000, p. 57)

Ora, seria a falta de uma compreensão processual das normas legais que em muitos casos propicia a formação de um hiato que separa a norma oficial e as práticas sociais. Bourdieu $(2009$, p.240) aponta para uma "confrontação constante entre as normas jurídicas e as práticas sociais". O mundo social seria ordenado por normas legais que através do poder simbólico passaria a exprimir a visão de mundo das classes dominantes, deslegitimando outros modos de estilo de vida. (BOURDIEU, 2009) A imposição de uma visão legítima no espaço social reflete a desigualdade de acesso ao capital e a força daqueles, que historicamente acumularam diferentes tipos de capital (econômico, social, cultural), possuem e que através das normas legais impõem um regime de verdade.

\section{As normas sociais e a constituição de um habitus sob a base da desigualdade social}

A força simbólica dos princípios de visão tem sua autoridade em ser reconhecidos e de impor o seu ponto de vista. (BOURDIEU, 2009) Na luta simbólica pela nominação legítima, os agentes investem o capital simbólico que adquiriram nas lutas anteriores e que pode ser juridicamente garantido, assim "a verdade do mundo social está em jogo nas lutas entre agentes que estão equipados de modo desigual para alcançar uma visão absoluta". Desta forma, o capital simbólico legalizado confere a apenas uma perspectiva, um valor absoluto, livrando-a da relatividade que é inerente a qualquer visão tomada a partir de um ponto particular do espaço social. (BOURDIEU, 2004)

Sendo assim, a "verdade" imposta está ligada a sistemas de poder que a produzem e ela se reproduz em um "regime da verdade". (FOUCAULT, 1979)Para o mesmo autor (1999), a verdade está relacionada ao poder, este analisado a partir de lutas cotidianas, da constituição no interior de uma trama histórica, que produz saberes e discursos. Assim, o poder se encarna nos corpos, nas práticas, nos gestos dos seres humanos, mas também nos pensamentos, nas representações e nas racionalizações e até no próprio reconhecimento de nós mesmos. (FOUCAULT, 1999) De acordo Foucault (1999, p.53):

\footnotetext{
La verdades de este mundo; es producidaen este mundo gracias a múltiplesimposiciones, y produceefectosreglados de poder. Cada sociedadposeesurégimen de verdad, su «política general de laverdad»: esdecir, define lostipos de discursos que acoge y hace funcionar como verdaderos; los mecanismos y las instancias que permiten distinguir losenunciados verdaderos o falsos, lamanera de sancionar a unos y a otros; las técnicas y losprocedimientos que son valorados enorden a laobtención de laverdad, el estatuto de quienes se encargan de decirqué es lo que funciona como verdadero.
}

Para Foucault (1999, p.172), existe a história da verdade baseada na história das ciências, mas por outro lado existem nas sociedades muitos outros lugares onde se forma a verdade, onde se definem uma série de regras do jogo a partir das quais surgem determinadas formas de subjetividade, determinados objetos, determinados tipos de saber, e a partir daí se pode realizar uma história externa, uma história exterior da verdade. ParaBourdieu (2004), ao lado da norma expressa e explicita ou do cálculo racional, também existem outros princípios geradores das práticas sociais. Segundo o autor (2004), o habitus como sistema de disposições para a prática, faz com que os agentes se comportem de determinada 
maneira em determinada circunstância .

A consciência de regras e normas é uma forma de presença social marcada por paradigmas e regras de ação colocadas pelo grupo e pela biografia do sujeito neste grupo. A consciência social compreende responsabilidade, que significa excluir possibilidades e isso está relacionado a formas de escolhas entre muitos modos de pensar, perceber, classificar, ordenar e praticar uma ação sobre o real. (DAMATTA, 1987)A conduta gerada pelo habitus não tem a regularidade das condutas deduzidas de um princípio legislativo, mas estão ligadas as situações constantemente renovadas, obedecendo a uma lógica prática, que define a relação cotidiana com o mundo. (BOURDIEU, 2004). A codificação visa à ordenação simbólica, mas quando se está diante de habitus diferentes, surge a possibilidade do conflito.

Segundo Bourdieu(2009), a normajurídica quando consagra um conjunto de regras sociais com caráter universalizante, para além das diferenças de condição e de estilo de vida, as mesmas possuiriam um efeito de normalização de uma cultura legítima que considera todas as práticas diferentes como desviantes, anômicas, e até mesmo anormais, patológicas. "No sistema social brasileiro, então, a lei, universalizante e igualitária é utilizada frequentemente para servir como elemento fundamental de sujeição e diferenciação política e social". (DAMATTA, 1997, p.237)Assim, codificar significa acabar com o fluido, o vago, as fronteiras mal traçadas e as divisões aproximativas, permite assim alcançar a calculabilidade e a previsibilidade. Além da clarificação e racionalização, há também uma eficácia simbólica que se revela a partir da violência que se exerce segundo as formas, construindo um discurso que é reconhecido como conveniente, legítimo, aprovado, uma vontade ou uma prática que, apresentada de outro modo, seria inaceitável. (BOURDIEU, 2004, p. $105-$ 106)

Segundo DAMATTA (1997), a sociedade brasileira se compõe por um universo social dual. A lei serviria para ordenar e massificar os indivíduos, que se tornam meros recipientes, sem história, relações sociais ou biografia. A aplicação do sistema legal não se faz em um vazio, mas em meio a relações de valores e ideologias. (DAMATTA, 1997) Diante da lei geral e impessoal que iguala juridicamente uma corrente de contra hábitos são criados para demarcar as diferenças, retomando sempre a hierarquização do mundo onde isso se torna possível. (DAMATTA,1997) O que se verifica na estrutura social do Brasil é que existem distintas formas de desigualdades que se constituem como base de construção para formas de vida, ou mesmo, de sobrevivência. Estes modos de vida não-legítimos estão quase sempre a um passo da ilegalidade. De acordo com Pinheiro (2000), na América Latina a lei teria caráter discriminatório para pobres e marginalizados, e seria fortalecida pela percepção negativa das elites em relação a estas populações.

\section{O espaço social brasileiro e as desigualdades de acesso ao capital}

\section{Revisitando a história do não-direito no Brasil}

A percepção do mundo social é produto de uma dupla estruturação: de um lado objetivo, porque as propriedades atribuídas aos agentes acontece de forma desigual, e também subjetiva, porque os esquemas de percepção e apreciação exprimem o estado das relações de poder simbólico. Esses dois mecanismos concorrem para produzir um consenso mínimo no mundo social, mas os objetos deste universo são percebidos e interpretados de formas diversas, porque sempre comportam uma parcela de indeterminação e fluidez e elasticidade semântica. (BOURDIEU, 2004) De acordo com Bourdieu (2004, p. 161):

Esse elemento objetivo de incerteza - que é muitas
vezes reforçado pelo efeito da categorização, podendo
a mesma palavra englobar práticas diferentes - fornece
uma base para a pluralidade de visões de mundo,
também ela ligada à pluralidade de pontos de vista. E,
ao mesmo tempo, uma base para as lutas simbólicas pelo
poder de produzir e impor a visão de mundo legítima.

Os agentes, mesmo os mais desprivilegiados, tendem a perceber o mundo como evidente e aceitálo, uma vez que as disposições perceptivas tendem a ajustar-se às posições no espaço social. (BOURDIEU, 2004) Desta forma, "se o mundo social tende a ser percebido como evidente e a ser apreendido, é porque as disposições dos agentes, o seu habitus, isto é, as estruturas mentais através das quais eles apreendem o mundo social, são em essência produto da interiorização das estruturas do mundo social". (BOURDIEU, 2004)

Na história brasileira, a criação jurídica reproduz relações sociais fundamentadas na hegemonia das oligarquias agroexportadoras ligadas aos interesses externos e adeptas do individualismo liberal, do elitismo colonizador e da legalidade lógico-formal. (WOLKMER, 2001) A dinâmica social no Brasil foi baseada na diferenciação social, que tem como foco o ataque às camadas populares, ou seja, o princípio de controle e normatização, aplicados pelo Estado, ocorre principalmente em relação aos grupos desprivilegiados. (PEDROSO, 2006) De acordo com Wolkmer (2001) nas sociedades industriais avançadas ocorre uma preocupação maior com uma ordem normativa caracterizada por funções distributivistas, persuasivas, promocionais e premiais. Já nas sociedades industriais periféricas e dependentes se caracteriza uma ordem normativa com funções coercitivas, repressivas e penais. 
Quando se fala da gênese de uma massa populacional marginalizada e excluída na sociedade brasileira, mister se faz remeter-se a um período escravocrata de não-direito, "em geral o escravo não tem leis." (MATTOSO, 2003, p.179) No século XIX, a partir de 1831, com a abolição do tráfico negreiro, a legislação autoriza a alforria dos escravos da nação. (MATTOSO, 2003) Apesar de ter sido mantido constantemente em recato, é inegável que o direito não-oficial da escravidão jamais deixou de existir, um exemplo foi a permanência do tráfico negreiro por longos anos, em situação de gritante ilegalidade. (COMPARATO, 2009)

O difícil caminho para a liberdade contou também com outros instrumentos legais como a Lei dos Sexagenários (1885), e a Lei do Ventre Livre (1871), que concedeu liberdade às crianças nascidas no país, de mãe escrava. (MATTOSO, 2003) Porém, a lei possuía cláusulas restritivas que obrigavam o senhor da mãe a educar a criança até os 8 (oito) anos e depois, teriam duas opções, receber do Estado uma indenização de 600 000 réis, e assim a criança passaria para uma instituição de caridade, que o faria trabalhar até os 21 anos, ou, o senhor poderia exercer o direito de utilizar os serviços do menor até 21 anos, ou seja, uma nova forma de escravidão, sem regulação do Estado. (MATTOSO, 2003)

A partir da Constituição de 1824, o escravo alforriado, nascido no Brasil, passa a ser considerado como cidadão, todavia com direitos limitados, como por exemplo, a exigência de renda para se tornarem cidadãos ativos, eleitor e elegível. (MATTOS, 2004) Segundo Mattoso (2003), em uma sociedade em que as relações se estabelecem pelo clientelismo e o paternalismo protetor, não se pode mensurar o número de alforriados que conseguiram elevar-se ao status humilde de eleitor primário.Assim, ser libertado não significava ser livre, somente na segunda ou terceira geração o sonho se completaria. Assim, a alforria não passava de um logro, simples questão de palavra, e o negro continuava devendo obediência, humildade e fidelidade aos poderosos. O liberto é repelido, marginalizado social e economicamente. (MATTOSO, 2003)

A preocupação do Poder Público com as mudanças de uma mão-de-obra escrava para a livre não estava relacionada com a manutenção da estrutura de produção e serviços urbanos, nem pelo controle e disciplinarização de condutas indesejáveis, mas tratavase de uma questão de poder e dominação que vai desde o lugar social que as populações negras iriam ocupar em uma nova ordem jurídico-formal, até a consequente necessidade de edificações de padrões modernos de urbanidade. (MATTOS, 2008) O crime passa a ser, não somente os atentados contra a pessoa e propriedade, ou ameaças à ordem instituída, mas também as ações e práticas contrárias a um novo mundo de trabalho que se descortina a partir do processo de transição da mão de obra. (MATTOS, 2008)

No final do século XIX, no processo de independência política, a luta antidiscriminatória estava presente com propostas de apagamento das diferenças entre os homens livres, o que não significava proposição efetiva a favor da abolição imediata da escravidão. (MATTOS, 2004) Para Mattos (2008), as práticas transgressivas das populações negras - sobretudo as escravizadas - são interpretadas como crimes que, no conjunto, remeteria a categoria de resistência com características multiformes à luta cotidiana contra a escravidão, instituíram modos de vida e sobrevivência como formas culturais próprias, alternativas a uma concepção hegemônica, "ordeira" e disciplinada de urbanidade. Ainda nos tempos do Império, um temor gerenciado pelo Estado - se fez presente na sociedade brasileira. As classes sociais mais baixas, compostas por indivíduos rotulados de marginais, eram perseguidas intensamente pela polícia, mesmo que não cometessem crime. Aliás, ser "marginal" constituía crime. Classificavam-se dessa forma os vadios, os capoeiristas, os escravos e os estrangeiros (PEDROSO, 2006).

Não ocorreram grandes mudanças políticas com a Proclamação da República em 1889. A política estava nas mãos dos mais ricos e centrada nos Estados brasileiros que apoiavam o Governo Central. Enquanto o Estado estabelecia sua concepção de ordem, o desvio, ou marginalidade, apresentava-se como condição obrigatória para milhares de indivíduos, que não conseguiam se inserir no trabalho assalariado. (PEDROSO, 2006) Esse mundo de desordem, construído no imaginário da elite do final do século XIX, nada mais era que o oposto do mundo do trabalho. Representava, dessa forma, o elemento fundamental para a reprodução das classes sociais. A existência do crime, da vagabundagem e da ociosidade justificava o discurso de exclusão e perseguição policial às camadas populares pobres e despossuídas. Assim, a segurança pública terminava por ditar a racionalidade do sistema. (PEDROSO, 2006) O século XX também é marcado pelo autoritarismo estatal, assim, acontecimentos como a Revolta da Vacina (1904), os massacres da Candelária, Vigário Geral e Eldorado dos Carajás (1993), são alguns exemplos que reafirmam a opressão em relação às populações periféricas.

\section{A Constituição de 1988 e a problemática da efetividade dos direitos sociais}

Ora, diante de uma caminhada de garantias e direitos tutelados no Brasil,a partir da Carta Cidadã de 1988, e diante da histórica e recorrente realidade desigual no país, onde se somam inúmeras denúncias de violações de direitos humanos ou ausência do Estado quanto à efetividade dos direitos sociais garantidos 
constitucionalmente,a delinquência e criminalidade fruto de um espaço social desigual quanto a ofertas de serviços públicos, as diferentes desigualdades que persistem entre brancos e negros, a letalidade seletiva da juventude negra de periferia, pergunta-se: os pilares doparadigma da racionalidade lógico-formal do direito monista devem ser mantidos? Ou, a própria formalização das pretensões sociais transformadas em direitos não devem ser também problematizadas? No Brasil, a cidadania civil e política não simbolizam a concretização de uma cidadania social . A desigual distribuição de podernassociedades latino-americanas, que tendem a se apresentar como democracias liberais, acaba por desafiar regularmente a igualdade de todos perante a lei.(PINHEIRO, 2000)

Assim, como assevera Capella (1998), o termo "todos" da igualdade capitalista moderna é a chave do mito da cidadania. Retornar ao paradigma monista pode enfraquecer o poder social e político de que os agrupamentos precisam para lutar contra a opressão Estatal. Desta forma, não basta se curvar ao manto constitucional da cidadania, mas analisar de forma crítica e reflexiva a produção das normas legais e a permanência das desigualdades no espaço social. De acordo com o mesmo autor (1998, p. 147):

A cidadania contempla, com os olhos prudentemente desentendidos do servo, a proliferação de novas misérias tecnológicas ou sociais: o tráfico de órgãos humanos, as manipulações genéticas, as acefalias por contaminação; o assassinatodecriançasabandonadas, ocrescimentodas máfias, a fome generalizada, os extermínios em massa. O catálogo de horrores do mundo desencantado, contemporâneo, de relações sociais universalizadas, estabelecidas insuportavelmente assim, ante as quais os seres humanos, como cidadãos, carecem de poder, com o perigoso engano de que a cidadania - universalista, ilustrada - chegue a parecer redundante.

O Brasil também assiste diariamente a força das arbitrariedades do Estado, com ou sem o manto legislativo. Em muitas localidades do Brasil, o Estado de Direito e o império da lei têm sua aplicabilidade limitada. Isto ocorre em virtude de continuar imperando em muitos municípios o clientelismo, em que relações pessoais imperam sobre instituições e a troca de favores perpetua concentrações extremas e duradouras de poder em poucas famílias ou grupos. A conquista de avanços sociais está diretamente relacionada a tais relações pessoais e tais trocas, o que - além de não ser legítimo ou ético - atenta contra a perspectiva de direitos. Neste contexto, a inclusão social é processo lento e demorado que não acompanha a vida das pessoas .

Segundo com o Informe 2016/2017 da Anistia Internacional, o que vimos em 2016 foi o desmantelamento de estruturas institucionais e programas que garantiam a proteção a direitos previamente conquistados, além da omissão do Estado em relação a temas críticos, como a segurança pública. Entre os retrocessos, o relatório lista a extinção do Ministério das Mulheres, Igualdade Racial e Direitos Humanos; e o anúncio de uma emenda constitucional (PEC 241/55) que limita os gastos do governo nos próximos vinte anos, em áreas cruciais como educação e saúde. A emenda já foi aprovada na Câmara dos Deputados e no Senado Federal, a despeito das pesadas críticas que recebeu da Relatoria Especial da ONU para Extrema Pobreza e Direitos Humanos. Outro retrocesso importante, de acordo com o relatório, foi a suspensão, em junho passado, de diversos acordos entre o governo federal e os governos estaduais para a implementação do programa de proteção aos defensores dos direitos humanos.

De acordo com o Relatório, a polícia continuou a fazer uso desnecessário e excessivo da força, em especial no contexto dos protestos. Jovens negros, principalmente os que moram em favelas e periferias, foram desproporcionalmente afetados pela violência por parte dos policiais. Defensores e defensoras dos direitos humanos, em especial os que defendem os direitos à terra e ao meio ambiente, enfrentaram cada vez mais ameaças e ataques. A violência contra as mulheres e crianças continua sendo uma prática comum. As violações de direitos humanos e discriminação contra refugiados, requerentes de asilo e migrantes se intensificaram.

\section{Complexidade e transdiciplinaridade: novos caminhos para o tempo presente}

Diante da complexidade que envolve o espaço social , nas diferentes relações sociais que se continuem, as normas legais precisam ser compreendidas para além de uma estrutura racional e formal . Para Bittar (2014, p.248), a ideia de que educação e racionalização relacionam-se a desenvolvimento, progresso e melhoria, precisa se desmitificada. Todo o projeto educacional induz valores, não há educação isenta. A racionalidade abarca a contradição da formação e de-formação, assim, quanto mais especialista, mais ignorante ou quanto mais racional, menos sentimental. A educação só teria sentido quando prepara para a mobilização, que instrumentalize mudanças, fugindo da mera repetição das formas de ação já conhecidas. (BITTAR, 2014)

A educação para a emancipação conscientiza do passado histórico, tornando-o presente, para análise da responsabilidade individual diante dos destinos coletivos futuros. A consciência da história deve ser trabalhada nos meios acadêmicos como forma de criar um enraizamento entre conceitos abstratos e tempo histórico-aplicativo. (BITTAR, 2014) Assim, "a descolorida apatia política, a invisibilidade dos problemas sociais, a indiferença social, a insatisfação sublimada no consumo, a inércia mobilizadora precisam ser superadas através de um movimento pedagógico que aja na contramão desse processo." (BITTAR, 2014, p.257)O educando precisa sentir-se tocada em diversas dimensões e de diferentes formas, a fim de despertar os próprios sentidos para a percepção do real, em direção à reconquista da subjetividade humanista, aunônoma, crítica e reflexiva. (BITTAR, 2014)

Para o autor, a recuperação da subjetividade depende do fortalecimento da autonomia, que somente se conquista pelo desenvolvimento da lucidez que 
decorre da capacidade crítico-reflexiva. (BITTAR, 2014)

"A racionalidade técnica não colabora para a melhoria das condições de análise do nosso tempo. Em poucas palavras, ela é a linguagem da própria dominação, e não condição paraa sua libertação". Desta forma, para se estudar a forma positivada de Direito necessário se faz a compreensão da organização social, das relações estruturais de poder, de valores e interesses que ele reproduz. (WOLKMER, 2001)

Diante da irregularidade do espaço social, a teoria da complexidade e transdisciplinaridade surgem em decorrência do avanço do conhecimento e do desafio que a globalidade coloca para o século XXI (SANTOS, 2008). O mundo, considerado sob o ângulo de suas regularidades, como que obedecendo a um princípio de ordem e de organização, é simples, com a condição de que seja visto dessa maneira. Ele se complexifica a partir do momento em que uma inteligência da desordem se elabora para refinar, enriquecer e tornar mais sutil o olhar que se dirige aos fenômenos (MORIN, 2013).Os postulados cartesianos de divisão das partes, ordenação dos objetos mais simples aos mais compostos e enumerações completas sobre o objeto. (DESCARTES, 1996) são contrapostos a religação dos saberes compartimentados, que oferece uma perspectiva de superação doprocesso de atomização. (SANTOS, 2008)

O ideal do conhecimento cientifico até o início do século XX, ainda presente no espírito científico, era revelar através da confusão dos fenômenos, as leis simples que os regem, a ordem pura que os determina, estabelecer verdades simples por quatro grandes meios: o princípio de ordem (contem o que é estável, o que é constante, regular, cíclico; princípio de separação (separa as matérias umas das outras, o objeto conhecido do sujeito conhecedor); princípio de redução (o conhecimento das unidades elementares permite conhecer os conjuntos dos quais elas são os componentes); princípio da validade absoluta da lógica clássica (dedutivo-indutivoidentitária). Durante o século XX esses princípios foram abalados com desenvolvimentoscientíficos como a termodinâmica, as descobertas da irradiação isotrópicas e a física quântica. O complexus significa "o que está ligado, o que está tecido", a complexidade reconhece a parcela inevitável de desordem e de eventualidade em todas as coisas, ela reconhece a parcela inevitável de incerteza no conhecimento. (MORIN, 2013)

A atual estrutura educacional, sedimentada com base em princípios seculares, tem levado os docentes a uma prática de ensino insuficiente para uma compreensão significativa do conhecimento (SANTOS, 2008), e também existe um distanciamento entre o saber ensinado e o universo dos alunos. Para Freire (1996), o ensino não pode alhear-se de todos os aspectos culturais, sociais e econômicos que circundam alunos, famílias e vizinhos. Diante da complexidade, que pode ser compreendida como uma relação entre o subjetivo e o objetivo, na busca da verdadeira interação de nosso tempo (MENDES, 2003) e irregularidade do espaço social, o estudo das estruturas sociais que operam na base de construção das normais legais é fundamental para se descortinar as linhas de força que operam no espaço social na luta pela imposição de um modo de vida legítimo, ao mesmo tempo em que o tecido social se perfaz em distintos estilos de vida.

A nova postura teórica que emerge vislumbra a ecologia de saberes como reconhecimento de que outras formas e critérios podem produzir conhecimento, e não apenas a ciência. Assim, a epistemologia deixa de ser uma disciplina normativa e passa a ser descritivointerpretativa, no reconhecimento do elo entre o sujeito que conhece e a realidade que se quer conhecer. (GIANNELLA, 2015) É uma disciplina que reconhece a pluralidade de "cosmovisões", ao invés de assumir de forma simplória a cosmovisão ocidental como a única digna de guiar o progresso da humanidade. A epistemologia contemporânea deixa de ser normativa e passa a ser dialógica, uma postura necessária na busca de outras relações entre seres humanos e entre eles e a natureza. Mudança importante para que possamos encontrar novas bases de integração e síntese onde antes existiu separação dicotômica e exclusão.(GIANNELLA, 2015)

De acordo com Morin e Moigne (2000, p. 91), “o conhecimento só pode ser pertinente se ele situar seu objeto no seu contexto e, se possível, no sistema global do qual faz parte, se ele cria uma forma incessante que separa e reúne, analisa e sintetiza, abstrai e reinsere no concreto". No paradigma emergente, o conhecimento é total e também local, constitui-se em redor de temas que em dado momento são adotados por comunidades interpretativas concretas como projetos de vidalocais, que podem ter como objetivos reconstituir a história de umlugar, manter um espaço verde, construir um computador adequado às necessidades locais, fazer baixar a taxa de mortalidade infantil, inventar um novo instrumento musical, erradicar uma doença etc. (SANTOS, 1988)

Novos caminhos para o estudo das normas legais sinalizam para a necessidade de uma atuação de caráter transdisciplinar no campo social, neste sentido, de acordo com Giannella (2007), trata-se de uma postura de busca livretranspondo os limites disciplinares postos, dos postulados indiscutíveis ou de qualquer legado conceitual que representa mais um hábito mental eque se apresenta como uma prisão mais do que uma fértil representação de nossa realidade. Trata-se de uma prática do transpassar os limites dados, de aproximar o que parece incongruente, de se abrir para a escuta dos contextos e dos sujeitos, relativizando nossas interpretações prévias a seu respeito e deixando que eles falem.O intercâmbio de saberes possibilita novos 
sentidos a todo processo de dinâmica social porque se fundamenta na valorização de todas as partes e nos diversos conhecimentos presentes no território, visando à construção de uma nova realidade, a partir de bases.A diminuição da força dos conhecimentos individualizados e científico só foi possível através do intercâmbio de ideias e decisões coletivas.

\section{Considerações finais}

O importante nesta dinâmica que envolve um universo mais amplo de saberes, para além do conhecimento disciplinar sobre as normas legais, seja dentro e/ou fora da Academia, é fomentar/construir um espaço participativo, que fomente as trocas de saberes, o diálogo, a escuta ativa, observando a realidade e seu contexto, buscando sempre atuações que possibilitem uma real transformação social e a diminuição do hiato existente entre a norma legal e a realidade social.

Busca-se uma formação crítica e histórica dos futuros operadores do direito para atuarem em um espaço social complexo e desigual, capacidade técnica e social importantes para o alcance de uma sociedade livre, justa e solidária, como definido pela Constituição da República Federativa do Brasil de 1988. Integrando ao conhecimento das normas legais os saberes advindos da pluralidade social, na tentativa de resgate do sujeito integral, de seus interesses, valores e anseios, possibilitando assim não apenas a inclusão, mas a transformação social.

\section{Referências bibliográficas}

BICHIERI, Cristina. Norms, conventions and the power of expectations.To appear in Philosophy of Social Science, N.Cartwright and E. Montuschi, eds., Oxford University Press. Fev 2013. Disponível: <https://sites.sas.upenn.edu/ behav-ethics/files/pss oxford feb.2013.pdf>. Acesso em: 18 set. 2017.

BITTAR, Eduardo C. B. O direito na Pós-modernidade. 3.ed. São Paulo: Atlas, 2014.

BOURDIEU, Pierre. O poder simbólico. Tradução: Fernando Tomaz. 12 ed. Rio de Janeiro: Bertrand Brasil, 2009.

Coisas ditas. Tradução: Cássia R. da Silveira e Denise Moreno Pegorin. São Paulo: Brasiliense. 2004

BRASIL. Constituição da República Federativa do Brasil: promulgada em 5 de outubro de 1988. Disponível em: BRASIL. Constituição (1988). Constituição da República Federativa do Brasil: promulgada em 5 de outubro de 1988. Disponível em: http://www.planalto.gov.br. Acessado em: 05 de set. de 2017. Acesso: 10 jan. 2018

CAPELLA, Juan Ramón. Os cidadãos servos. Porto Alegre: Fabris, 1998.

CAPRA, Fritjof. O ponto de mutação. São Paulo: Cultrix, 1983.

COMPARATO, Fábio Konder. Dossiê Crise do Congresso. Revista Estudos Avançados. v.23.2009.

DAGNINO, Evelina. Políticas culturais, democracia e projeto neoliberal. In: Rio de Janeiro, (15): 45-65, janeiro / abril de 2006. Disponível em: <http:// www.forumrio.uerj.br/documentos/revista_15/15_dossie_EvelinaDagnino. pdf. Acesso em: 21 fev. 2018.
DAMATTA, Roberto. Relativizando: uma introdução à antropologia social. Rio de Janeiro: Rocco. 1987.

Carnavais, Malandros e Heróis: para uma sociologia do dilema brasileiro.6 ${ }^{\text {a }}$ ed. Rio de Janeiro: Rocco. 1997.

DESCARTES, René. Discurso do Método. São Paulo: Martins Fontes. 1996.

FOUCAULT, Michel. Microfísica do Poder. Trad. Roberto Machado. Rio de Janeiro: Edições Graal, 1979.

Estratégias de poder. Obras essenciais. V. II. EdicionesPaidós Ibérica, S.A: Barcelona, 1999.

FREIRE, Paulo. Pedagogia da Autonomia: saberes necessários à prática educativa. 36a edição. São Paulo: Paz e Terra, 1996.

GIANNELLA, Valéria. O nexo pesquisa-ação: qual conhecimento para que políticas? In: Gestión Local deldesarrollo y lucha contra la pobreza. Aportes para elfortalecimiento de lainvestigación y las políticas en América Latina. Luiz Carrizo (Editor), Manoel CarbalhaEdición. Montevidéo, 2007.

Epistemoloque? epistemologia para não filósofos, guiando a ação para o tempo que vem. Revista UFG - Dossiê ECOTRANSD: Ecologia dos saberes e Transdisciplinaridade, v. 5, n. 1, 2015.

MATTOS, Hebe Maria. Escravidão e cidadania no Brasil monárquico. $2^{\mathrm{a}}$ ed., Rio de Janeiro: Jorge Zahar Ed, 2004.

MATTOS, Wilson Roberto de. Negros contra a ordem: astúcias, resistências e liberdades possíveis (Salvador, 1850-1888). Salvador:EDUNEB, EDUFBA, 2008 .

MATTOSO, Kátia M. de Queirós. Ser escravo no Brasil. Trad. James Amado. São Paulo: Brasiliense, 2003.

MENDES, Cândido. Representação e Complexidade na Agenda do Milênio. In: Representação e Complexidade. Candido Mendes (org); Enrique Lareda (ed.). Rio de Janeiro: Garamond. 2003.

MORIN, Edgar; MOIGNE, Jean Louis.A inteligência da complexidade. Fundação São Paulo: Peirópolis. 2000.

MORIN, Edgar, CLOTET, Joaquim, SILVA, Juremir Machado da.As duas globalizações: complexidade e comunicação, uma pedagogia do presente. $3^{\mathrm{a}}$ ed. Porto Alegre: Sulina, EDIPUCRS, 2007.

MORIN, Edgar. A religação de saberes. Rio de Janeiro: Bertrand Brasil. 2013.

PEDROSO, Regina Célia. Violência e Cidadania no Brasil: 500 anos de exclusão. São Paulo: Ática, 2006.

PINHEIRO, Paulo Sérgio. Democracia, violência e injustiça: o Não - Estado de Direito na América Latina. Org. Juan E. Méndez, Guilhermo O’Donnell, Paulo Sérgio Pinheiro, trad. Ana Luiza Pinheiro, Octacilio Nunes, São Paulo: Paz e Terra, 2000.

REALE, Miguel. Lições Preliminares de Direito. São Paulo: Saraiva. 2002.

Experiência e Cultura. Campinas: Bookseller, 2000.

SANTOS, Akiko. Complexidade e transdisciplinaridade em educação: cinco princípios para resgatar o elo perdido. Revista Brasileira de Educação. v. 13. $n^{\circ} 37$. jan/abr. 2008.

SANTOS, Boaventura de Sousa. Por uma concepcão multicultural de direitos humanos. Revista Crítica de Ciências Sociais. Nº48. Junho 1997.p.13.

STRAUSS, Anselm; CORBIN, Juliet. Bases de lainvestigacióncualitativa: técnicas e procedimentos para desarrollarlateoría fundamentada. Trad: Eva Zimmerman. Colombia: Editorial Universidad de Antioquia, deciembre, 2002.

WOLKMER, Antônio Carlos. Pluralismo Jurídico: Fundamentos de uma nova cultura no Direito. São Paulo: Editora Alfa Ômega. 2001. 


\section{Notas}

1. O reconhecimento da complexidade significa confessar a dificuldade de descrever, de explicar, é exprimir que um objeto apresenta traços diversos, multiplicidade e indistinção. (MORIN, 2000, p. 90-91)

2. A força da univocidade, da estabilidade, da racionalidade formal, da certeza e da segurança jurídica fundamenta-se na moderna cultura ocidental, a partir do século XVII e XVIII, e corresponde a uma visão de mundo burguesa, do modo de produção capitalista, da ideologia liberal-individualista, com a forma de organização institucional de poder (Estado-Soberano) que passa a ser configurada na dominação racional-legal. (WOLKMER, 2001, p. 26)

3. Segundo Capra (1983, p.243-244), a nova cultura que está emergindo compartilha uma visão de realidade que se consolidará como um novo paradigma, destinado a eclipsar a visão de mundo cartesiana em nossa sociedade. E se constituirá de forma ecológica, uma nova visão da realidade que se baseia na consciência do estado de inter-relação e interdependência essencial de todos os fenômenos — físicos, biológicos, psicológicos, sociais e culturais.

4. "Lo más problable és que la teoria derivada de losdatos se parezca más com la "realidad" que la teoria derivada de unir una serie de conceptos basados em experiencias o solo especulando (cómopiensa uno que las cosas debieran funcionar). Debido a que las teorias fundamentadas se basan em losdatos, és más posible que generenconocimientos, aumentenlacomprensión y proporcionen una guia significativa para laacción.” (STRAUSS, 2012, p.14)

5. Corrente filosófico-jurídica que apresentava os fatos jurídicos estabelecendo uma descrição da realidade que se desenvolveu sob a influência do positivismo e da sociologia "empírico-naturalista". (REALE, 2000)

6. Corrente filosófico-jurídica que considera a realidade apreendida a partir de certos princípios a priori, em que a forma determina o que é jurídico. (REALE, 2000)

7. Poder de enunciação do mundo só seria possível quando ignorado como arbitrário, este poder de construção da realidade para a criação de uma ordem seria chamado de poder simbólico. (BOURDIEU,2009)

8. As relações objetivas estão relacionadas a posições ocupadas nas distribuições e concorrência pela apropriação dos recursos no universo social. Esses poderes sociais fundamentais referem-se ao capital econômico, em suas diferentes formas, que se revestem as diferentes espécies de capital quando percebidas e reconhecidas como legítimas, como o capital cultural, além do capital simbólico. (BOURDIEU, 2004)

9. O poder simbólico pode ser compreendido como o poder de constituir o dado pela enunciação, fazendo assim confirmar ou de transformar a visão de mundo e, consequentemente, a ação sobre o mundo, poder este ignorado como arbitrário, definindo uma relação determinada entre os que exercem o poder e os que lhe estão sujeitos. (BOURDIEU, 2009)

10. Outro termonormas sociaistambém se relaciona com os modos de agir e pensar influenciados por dada coletividade. De acordo com Bichieri $(2013$, p. 1), entende-se por normas sociais: [...] um padrão de comportamento tal que as pessoas têm uma preferência para seguir esse padrão quando acreditam que muitas das pessoas de sua rede de referência comportam-se desse jeito, muitas pessoas da sua rede de referência acham que pessoas como elas deveriam comportar-se desse jeito.

11. Percepção dos pobres como classes perigosas. (PINHEIRO, 2000)

12. Concedidas a partir de 1831 , as cartas de alforria demostravam a mentalidade escravista dos senhores que, mesmo sem a necessidade de justificar a liberdade concedida, gostavam de externalizar que agiam de acordo com o bom direito e a estrita equidade. (MATTOSO, 2003)

13. O Estado brasileiro, em sua origem histórica, passa a organizar a sociedade de uma maneira desigual, tanto por possibilitar aos grupos dominantes locais e espaços de poder privilegiado dentro dessa dinâmica, como por distribuir recursos e serviços deste Estado, como educação e saneamento básico,saúde, de maneira desigual ao longo de sua formação e estruturação. SANTOS, Everton. Brasil: herança cultural e desafios do presente. Revista Sociedade e Contemporaneidade, Canoas: IBPEX, 2008, p.183.

14. Compreendido como multicultural, que prevê uma relação equilibrada e mutuamente potenciadora entre a competência global e a legitimidade local, que constituem os dois atributos de uma política contra-hegemônica de direitos humanos no nosso tempo. (SANTOS, 1997)

15. O reconhecimento da origem transversal do problema da delinquência e criminalidade exige a coordenação de ações intersetoriais que perpassam as áreas de educação, saúde, habitação, cultura, esportes e mercado de trabalho, entre outras. Nota Técnica, $\mathrm{n}^{\circ} 18$, IPEA - Indicadores Multidimensionais de Educação e Homicídios e Territórios nos Territórios Focalizados pelo Pacto Nacional pela Redução de Homicídios. Março, 2016, Brasília. p.10. Disponível em: http://www.ipea.gov.br/portal/index. php?option $=$ com content\&view $=$ article $\&$ id= $=27714$. Acesso em: 21 fev. 2018.p.10.

16. As desigualdades de oportunidades permanecem renitentes entre brancos, pretos e pardos. Além de nascerem em condições socioeconômicas piores, pretos e pardos são mantidos nestas condições, sendo impedidos de ascenderem socialmente. É bastante provável que mecanismos de discriminação racial sejam operantes na manutenção das desvantagens que incidem sobre pretos e pardos em relação aos brancos.LEÃ O, Natáliaet al. Relatório das Desigualdades de Raça, Gênero e Classe (GEMAA), n. 1, 2017, pp. 1-21. Disponível em: http://gemaa.iesp.uerj.br/relatorios/relatoriodas-desigualdades-gemaa-no-1/. Acesso em: 21 Fev. 2018.

17. Um indivíduo afrodescendente possui probabilidade significativamente maior de sofrer homicídio no Brasil, quando comparado a outros indivíduos. Aos 21 anos de idade, quando há o pico das chances de uma pessoa sofrer homicídio no Brasil, pretos e pardos possuem $147 \%$ a mais de chances de ser vitimados por homicídios, em relação a indivíduos brancos, amarelos e indígenas. Nota Técnica. $\mathrm{N}^{\mathrm{o}}$ 17. Atlas da Violência 2016. Brasília, 2016 Instituto de Pesquisa Econômica Aplicada - IPEA e Fórum Brasileiro de Segurança Pública. Disponível em: http://www.ipea.gov.br/ portal/images/stories/PDFs/nota_tecnica/160405 nt_17 atlas da violencia_2016 finalizado.pdf. p. 8 . Acesso em $21 \overline{\mathrm{Fev}}$. $2 \overline{0} 18$.

18. A racionalidade formal conjugada com a força da univocidade, da estabilidade, da certeza e da segurança jurídica, fundamenta-se na moderna cultura ocidental, a partir do século XVII e XVIII, e corresponde a uma visão de mundo burguesa, do modo de produção capitalista, da ideologia liberal-individualista, com a forma de organização institucional de poder (Estado-Soberano) que passa a ser configurada na dominação racional-legal. (WOLKMER, 2001, p.26)

19 O Direito como produção exclusiva do Estado é modelo normativo que vem dominando, em fins do século XX, os países da Europa Central e América Latina. (WOLKMER, 2001, p.80)

20. De acordo comDagnino (2006, p.154), a noção de cidadania pressupõe um processo de afirmação e reconhecimento de direitos, em que busca-se um projeto para uma nova sociabilidade, com bases mais igualitárias nas relações sociais. Também implica no "reconhecimento do outro como sujeito portador de interesses válidos e de direitos legítimos", busca-se a participação efetiva dos cidadãos no poder, em uma tentativa de reinvindicação ao acesso, a inclusão, a participação e ao pertencimento a um sistema político já dado.

21. Caderno de Educação em Direitos Humanos. Educação em Direitos Humanos: Diretrizes Nacionais. Secretaria de Direitos Humanos da Presidência da República. Brasília. 2013. p. 21.

22. Anistia Internacional. Informe 2016/17. O Estado dos Direitos Humanos no Mundo. p.38.

23. O termo pode ser entendido como um espaço multidimensional de posições, um campo de forças impostas e irredutíveis às intenções dos agentes individuais ou mesmo às interações diretas entre os agentes. (BOURDIEU, 2009) 
24. O sistema do racional induz um estilo de prática que se modela sobre o comportamento dos objetos, isso acarreta uma objetivação do mundo da ação, levando a uma redução sistemática das significações, essa última entendida como uma relação que remete de uma fala, um ato, um objeto, de uma situação a outros elementos do campo da experiência. (MORIN, 2013)

25. A força da univocidade, da estabilidade, da racionalidade formal, da certeza e da segurança jurídica fundamenta-se na moderna cultura ocidental, a partir do século XVII e XVIII, e corresponde a uma visão de mundo burguesa, do modo de produção capitalista, da ideologia liberal-individualista, com a forma de organização institucional de poder (Estado-Soberano) que passa a ser configurada na dominação racional-legal. (WOLKMER, 2001)

26. A complexidade negocia com a incerteza, não para exorcizá-la, o que seria impossível, mas na perspectiva do estabelecimento de ponte provisórias entre o ser que busca e o desconhecido. A complexidade implica afrontar as verdades caseiras, as certezas confortáveis, e, por vezes, até mesmo os ideais mais caros e aparentemente generosos (MORIN, CLOTET, 2007).

27. O conhecimento do paradigma emergente tende assim a ser um conhecimento nãodualista, um conhecimento que se funda na superação das distinções tão familiares e óbvias que até há pouco considerávamos insubstituíveis, tais como natureza/ cultura, natural/ artificial, vivo/inanimado, mente/matéria, observador/observado, subjetivo/objetivo, coletivo/individual, animal/pessoa (SANTOS, 1988).

28. De acordo com Giannella(2007, p.13-14), precisamos entender a insuficiência do objetivismo, e compreender a complexidade e multidimensionalidade do real, a possibilidade de uma visão integrada. Precisamos construir coletivamente a direção e o sentido de nossas ações, pois o conhecimento científico não é tido mais, automaticamente, como dono da Verdade e vem recolocado no meio de muitas outras formas de fazer sentido do mundo. 